\begin{tabular}{|c|l|}
\hline Title & Double SCN5A mutation underlying asymptomatic Brugada syndrome \\
\hline Author(s) & $\begin{array}{l}\text { Yokoi, Hisataka; Makita, Naomasa; Sasaki, Koji; Takagi, Y asuhiro; Okumura, Y asuo; Nishino, Tetsuo; Makiyama, } \\
\text { Takeru; Kitabatake, A kira; Horie, Minoru; Watanabe, Ichiro; T sutsui, Hiroyuki }\end{array}$ \\
\hline Citation & $\begin{array}{l}\text { Heart Rhythm, 2(3), 285-292 } \\
\text { https://doi.org/10.1016/.hrthm.2004.11.022 }\end{array}$ \\
\hline Issue Date & 2005-03 \\
\hline Doc URL & http:/hdl.handle.net/2115/16957 \\
\hline Type & article (author version) \\
\hline File Information & H RHY THM2-3.pdf \\
\hline
\end{tabular}

Instructions for use 


\section{A Double SCN5A Mutation Underlying Asymptomatic Brugada Syndrome}

\section{Revised Manuscript \#HR-040339}

Hisataka Yokoi, MD, $\mathrm{PhD}^{1}$, Naomasa Makita, $\mathrm{MD}, \mathrm{PhD}^{1}$, Koji Sasaki, MD, $\mathrm{PhD}^{1}$, Yasuhiro Takagi, $\mathrm{MD}, \mathrm{PhD}^{2}$, Yasuo Okumura, $\mathrm{MD}, \mathrm{PhD}^{2}$, Tetsuo Nishino $\mathrm{MD}^{3}$, Takeru Makiyama $\mathrm{MD}^{4}$, Akira Kitabatake, $\mathrm{MD}, \mathrm{PhD}^{1}$, Minoru Horie, $\mathrm{MD}, \mathrm{PhD}^{5}$, Ichiro Watanabe, $\mathrm{MD}, \mathrm{PhD}^{2}$ Hiroyuki Tsutsui, $\mathrm{MD}, \mathrm{PhD}^{1}$

1. Department of Cardiovascular Medicine, Hokkaido University Graduate School of Medicine, Sapporo, Japan

2. Division of Cardiovascular Disease, Department of Medicine, Nihon University School of Medicine, Tokyo, Japan

3. NTT Sapporo Hospital, Sapporo, Japan

4. Department of Cardiology, Kyoto University Graduate School of Medicine, Kyoto, Japan

5. Department of Cardiovascular and Respiratory Medicine, Shiga University of Medical Science, Shiga, Japan

Words: Abstract 247, Text 3560
書式変更：フォント：太字 書式変更：フォント：太字 書式変更：中央揃え 書式変更：フォント：太字 書式変更：フォント：太字 
Acknowledgments: This work has been supported by the research grants 15090711 (NM)

and $14370225(\mathrm{MH})$ from the Ministry of Education, Culture, Sports, Science and Technology, Japan, and the research grants for cardiovascular diseases (13A-1) (16B-3) from the Ministry of Health, Labour and Welfare, Japan (NM and MH), Japan Research Foundation for Clinical Pharmacology, and Takeda Science Foundation (NM).

\section{Address for correspondence:}

Naomasa Makita, MD, PhD

Department of Cardiovascular Medicine, Hokkaido University Graduate School of Medicine,

Kita-15, Nishi-7, Kita-Ku, Sapporo 060-8638, Japan.

Phone: +81-11-706-6973, FAX: +81-11-706-7874, e-mail: makitan@med.hokudai.ac.jp 


\section{Abstract}

Objective/Background: Patients with the Brugada syndrome who experience syncope or aborted sudden death are at high risk for recurrent lethal arrhythmias. However, the prognosis and the therapeutic approaches in asymptomatic individuals with a Brugada-type ECG (asymptomatic Brugada syndrome) are controversial.

Methods/ Results: We genetically screened 30 asymptomatic probands (male 29, female 1; mean age, 47.1 years) exhibiting a spontaneous Brugada-type ECG. Family members of patients with the Brugada syndrome were excluded. Twenty-nine of 30 patients $(96.7 \%)$ remained free from symptoms for at least three years. One patient (case \#1) who had a family history of sudden death died suddenly during sleep. Ventricular fibrillation was induced by programmed electrical stimulation in 14 of 18 subjects (78\%), but none of these 18 subjects developed spontaneous ventricular arrhythmias. Genetic screening failed to identify SCN5A mutations in most cases, but demonstrated a novel double missense mutation (K1527R and A1569P) located on the same allele in another asymptomatic subject (case \#2).

Heterologously expressed mutant $\mathrm{Na}$ channels exhibited a negative shift of steady-state inactivation $(9.2 \mathrm{mV})$ and enhanced slow inactivation, suggesting that this individual harbors a subclinical channel dysfunction compatible with symptomatic Brugada syndrome.

Conclusions: Asymptomatic individuals with a Brugada-type ECG generally have a better 
prognosis than their symptomatic counterparts, but there may be a subgroup of these

individuals with poor prognosis. Severe Na channel dysfunction due to SCN5A mutations may not be sufficient to cause symptoms or arrhythmias in the Brugada syndrome, suggesting some unknown factors or modifier genes influencing the arrhythmogenesis.

Key Words: Brugada syndrome, Asymptomatic mutation carrier, Patch clamp, Sodium channel, Genetics, Slow inactivation, SCN5A, Ventricular fibrillation

\section{List of abbreviations used in the manuscript}

VF: Ventricular fibrillation, SCN5A: The gene encoding human cardiac voltage-gated sodium channel $\alpha$ subunit (Nav1.5), SUNDS: Sudden unexplained nocturnal death syndrome, PES:

Programmed electrical stimulation, PCR: Polymerase chain reaction, SSCP: Single-strand conformational polymorphism, WT: Wild-type, $\mathrm{V}_{1 / 2}$ : The voltages for half maximal inactivation or conductance, NS: no significant difference 


\section{INTRODUCTION}

The Brugada syndrome is a primary electrical disorder without underlying structural heart diseases characterized by the coved-type or saddle back-type ST elevation in the right precordial leads ${ }^{1,2}$. It predisposes affected individuals to ventricular fibrillation (VF), and patients with aborted sudden cardiac death are candidates for implantation of a defibrillator because of a high risk of recurrent ventricular arrhythmias. Mutations in the cardiac $\mathrm{Na}$ channel $\alpha$ subunit gene (SCN5A) are identified in some patients with the Brugada syndrome, and heterologously expressed mutant Na channels exhibit biophysical abnormalities resulting in reduced cardiac Na current ${ }^{3}$.

Sudden unexplained nocturnal death syndrome (SUNDS) is one of the leading causes of sudden death in young or middle-aged men in Japan and Southeast Asian countries.

Although SUNDS is recognized as phenotypically and genetically equivalent to the Brugada syndrome ${ }^{4}$, its electrocardiographic manifestations, especially among those with sudden death as the first event, are often uncertain unless they have a strong family history or have been resuscitated from sudden death. Recent studies have revealed that the prevalence of a Brugada-type ECG is $0.1-0.7 \%$ in the general population in Asia and other countries ${ }^{5-7}$. However, the pathophysiology, prognosis, and the therapeutic approaches in asymptomatic 
individuals exhibiting a Brugada-type ECG are controversial. Brugada et al. showed that the prognosis of this patient group is unfavorable; sixteen of the 111 (14\%) asymptomatic individuals with a spontaneous abnormal ECG had arrhythmic events during the follow-up period of $27 \pm 29$ months $^{8}$. In contrast, Priori et al. found no episodes of malignant arrhythmias over a period of 3 years in 30 asymptomatic patients with a Brugada sign ${ }^{9}$. A very low rate of arrhythmic events in this patient group has been confirmed by multiple recent and larger-scale studies ${ }^{7,10-13}$. In one study of 14,000 individuals in Japan, the mortality rate of 98 subjects with a Brugada sign was not higher than the rest of the cohort ${ }^{7}$. Despite the discrepancy in prognosis among different studies, there is evidence that some asymptomatic individuals with a Brugada-type ECG tend to die suddenly during sleep, a clinical observation characteristic of SUNDS, suggesting that SUNDS may underlie at least a part of Brugada-type ECG.

In the present study, we have clinically evaluated and genetically analyzed 30 asymptomatic individuals with a Brugada-type ECG who lacked a family history of the Brugada syndrome to eliminate individuals with an apparent genetic background. Twenty-nine of 30 patients remain asymptomatic during the follow-up period with the exception of one case of sudden death. In this case, the victim had a family history of sudden death (not the Brugada syndrome). We found a double SCN5A mutation in another asymptomatic subject without family history of sudden death that exhibited $\mathrm{Na}$ channel 
dysfunction characteristic for the symptomatic Brugada syndrome. At least some asymptomatic subjects with a Brugada-type ECG have severe Na channel dysfunction, but they do not necessarily manifest arrhythmias. Clinical consequence and arrhythmogenesis in the Brugada syndrome may be greatly influenced by some unknown environmental factors or modifier genes.

\section{Methods}

1. Patient population

The study population consists of 30 asymptomatic probands with Brugada-type ECG who agreed to genetic testing. The ECG criteria are (1) J wave elevation higher than $0.2 \mathrm{mV}$ and ST elevation higher than $0.1 \mathrm{mV}$ in $\mathrm{V}_{1}-\mathrm{V}_{3}$, (2) no demonstrable underlying heart disease evaluated by echocardiography. Family members of the Brugada syndrome, and patients that exhibited transient Brugada-type ST elevation only during drug exposure were excluded. No patient had received antiarrhythmic drugs. Programmed electrical stimulation (PES) and drug provocation tests using pilsicainide or flecainide were performed in 18 and 17 patients, respectively. Patients were followed up for 2 to 6 years. 


\section{PES}

PES was performed in the fasting state, after obtaining written informed consent. The protocol of ventricular stimuli included up to three extra stimuli (two basic cycle lengths of $600 \mathrm{~ms}$ and $400 \mathrm{~ms}$ ) with the coupling interval of the extra stimuli not shorter than $200 \mathrm{~ms}$.

VF was induced from the right ventricular apex or right ventricular outflow tract.

\section{Genetic screening of SCN5A}

Genomic DNA was extracted from peripheral blood by using PURGEGE DNA isolation kit (Gentra Systems). The SCN5A exons and flanking introns were amplified by PCR as previously described ${ }^{14}$. Genetic screening was performed by PCR-single-strand conformational polymorphism (PCR-SSCP) analysis ${ }^{15}$ or direct sequencing. PCR-amplified samples were run on a non-denatured $8 \%$ polyacrylamide gel with or without $10 \%$ glycerol at $160 \mathrm{~V}$ for 2-3 hrs, and the gels were visualized by silver staining (Daiichi Pure Chemicals, Tokyo). DNA sequencing was performed using an ABI PRISM 310 genetic analyzer (Applied Biosystems). Genetic analysis was carried out according to the protocol approved by the ethics committee of Hokkaido University Graduate School of Medicine. Written informed consent was obtained from all subjects.

4. Construction of the mutant $\mathrm{Na}$ channel plasmid 
The mutant Na channel cDNA was constructed by the overlapping-extension PCR strategy ${ }^{15}$ using the human Nav1.5 cDNA as a template. A missense mutation K1527R was introduced by two rounds of PCR between nt. 4142 and 4770 (628 bp). Similarly, another mutation A1569P was introduced between nt. 4418 and 5027 (609 bp). The PCR fragments of K1527R and A1569P were digested with KpnI/BstEII (403 bp) and BstEII/BamHI (300 bp), respectively, and assembled back into the wild-type (WT) Nav1.5 cDNA which was subcloned in the mammalian expression plasmid pRcCMV (Invitrogen). Correct assembly of the mutant channel plasmid was verified by sequencing to identify clones without polymerase errors. We constructed the plasmid for the double mutation (K1527R plus A1569P) only, because we found that the mutations of K1527R and A1569P are located on the same allele (see Results).

The human cell line tsA-201 was transiently transfected with either WT or mutant plasmids in combination with a plasmid encoding CD8 (pCD8-EBO-Leu2) to visually identify transfected cells using Dynabeads (M-450 CD8, Dynal) ${ }^{16}$. To evaluate the effects of $\beta_{1}$ subunit, the pCD8-EBO-Leu2 was replaced by a bicistronic plasmid encoding both CD8 and human $\beta_{1}$ subunit (pCD8-IRES-h $\beta_{1}$ ). Na currents were recorded 24 to 48 hours after transfection using the whole-cell patch-clamp technique. The pipette solution contained 10 mM NaF, 110 mM CsF, 20 mM CsCl, 10 mM EGTA, and 10 mM HEPES (pH adjusted to 
7.35 with $\mathrm{CsOH}$ ) and the bath solution contained $145 \mathrm{mM} \mathrm{NaCl}, 4 \mathrm{mM} \mathrm{KCl}, 1.8 \mathrm{mM} \mathrm{CaCl}_{2}, 1$ $\mathrm{mM} \mathrm{MgCl} 2,10 \mathrm{mM}$ glucose, and $10 \mathrm{mM}$ HEPES (pH 7.35 with $\mathrm{NaOH}$ ). The holding potential was $-120 \mathrm{mV}$, and the recordings were performed at room temperature. Data acquisition and analysis were accomplished by pClamp 6 or 8 (Axon Instruments) and SigmaPlot (SPSS Science). Results are presented as mean \pm SEM unless otherwise stated, and statistical comparisons were made using the unpaired Student's $t$ test. Statistical significance was assumed for $\mathrm{p}<0.05$.

\section{Results}

1. Clinical characteristics of the patients (Table 1)

Thirty asymptomatic probands with Brugada-type ECG (male 29, female 1; mean age $47.1 \pm 9.5$ years (mean $\pm \mathrm{SD}$ ), ranging 28 - 68) were enrolled. Family history of unexplained sudden death (but not Brugada syndrome) was documented in 2 individuals. Intravenous administration of pilsicainide or flecainide $(1 \mathrm{mg} / \mathrm{kg})$ exacerbated ST elevation (> $0.2 \mathrm{mV}$ ) in 15 of 17 patients (88\%). VF was induced by PES in 14 of 18 patients (78\%). Two patients with positive tests for both drug provocation test and PES received an implantable cardioverter defibrillator (ICD), but their discharges have not been recorded. One patient (case \#1) died suddenly during sleep and an SCN5A mutation was identified in one patient 
(case \#2).

Case \#1.

A 43-year-old Japanese man who was pointed out as Brugada-type ECG at a regular medical check up. He had no history of syncope or palpitation. His father had died suddenly of acute myocardial infarction at the fourth decade of life, but his clinical record is not available. Twelve-lead ECG showed coved-type ST elevation in $\mathrm{V}_{1-3}$ (Fig. 1A). Chest X-ray and echocardiography were normal. The patient accepted genetic testing but declined further examinations including PES or drug provocation tests. Two years later in the morning, he was found dead in bed. No SCN5A mutation was found in this case.

Case \#2.

A 60-year-old Japanese man. Coved-type ST elevation in $\mathrm{V}_{1-3}$ was indicated at the preoperative ECG check-up when he was 55 years old. He had no palpitation, syncope, nor family history of sudden death. He was admitted to the hospital for further examinations. Coved-type ST elevation was evident in $\mathrm{V}_{1-3}$ (Fig 1B). Structural heart diseases were excluded by chest X-ray and echocardiography. Late potentials by signal-averaged ECG were positive (filtered QRS=119 ms, under $40 \mu \mathrm{V}$ duration $=57 \mathrm{~ms}, \mathrm{RMS}_{40}=5.5 \mu \mathrm{V}$ ), and intravenous administration of $50 \mathrm{mg}$ flecainide augmented $\mathrm{ST}$ elevation in $\mathrm{V}_{1-3}$. VF was induced by 
double extra stimulations at the right ventricular outflow tract. He was advised for implantation of an ICD, but he declined it. He has been free from symptoms for 3 years.

2. Genetic analysis of the case \#2

PCR-SSCP analysis showed an aberrant conformer in exon 27 of case \#2 (Fig 2A).

Direct sequence confirmed two heterozygous base substitutions A4580G and G4705C,

leading to amino acid substitutions of Arg for Lys-1527 (K1527R) and Pro for Ala-1569

(A1569P), respectively (Fig. 2B). His family members declined further examinations

including DNA diagnostics. In order to determine whether these mutations are located on one allele (double mutation) or on different alleles (compound mutations), PCR fragment of exon 27 was subcloned into a vector pGEM-T easy (Promega), and multiple independent clones were sequenced. Approximately $50 \%$ of the clones showed wild-type sequence, and the rest of the clones showed both mutations K1527R and A1569R (data not shown), indicating that two mutations are located on the same allele, but not compound mutations. Although genomic information of his family members is not available, two mutations were most likely inherited from one of his parents. Furthermore, neither K1527R nor A1569R was observed in 500 normal chromosomes, excluding the possibility of DNA polymorphisms. 
2. Biophysical properties of the double mutant channel

Whole-cell Na currents of the $\mathrm{K} 1527 \mathrm{R}+\mathrm{A} 1569 \mathrm{P}$ mutant channel heterologously

expressed in tsA-201 cells showed current decay nearly indistinguishable from WT (Fig 3A).

Persistent Na current, a biophysical property most commonly observed in mutant Na channels responsible for type-3 long QT syndrome (LQT3) ${ }^{17}$, was not evident in the mutant , channel.

削除: KR/AP

Conductance-voltage (GV) curve showed that the slope factor $k$ of the mutant channel was

significantly larger than that of WT (WT: $5.3 \pm 0.3 \mathrm{mV}, \mathrm{n}=9 ; \mathrm{K} 1527 \mathrm{R} \pm \mathrm{A} \underline{1569 \mathrm{P}:} 7.8 \pm 0.8 \mathrm{mV}$, $\mathrm{n}=8 ; \mathrm{p}<0.01)$, whereas the voltages for the half maximal conductance $\left(\mathrm{V}_{1 / 2}\right)$ were comparable

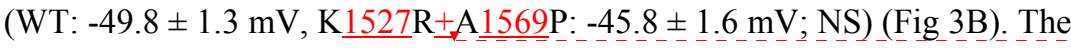
voltage-dependence of fast inactivation was significantly shifted in a hyperpolarizing direction by $9.2 \mathrm{mV}$ in the mutant than $\mathrm{WT}\left(\mathrm{V}_{1 / 2} ; \mathrm{WT}:-88.6 \pm 1.0 \mathrm{mV}, \mathrm{n}=9\right.$;

$\mathrm{K} 1527 \mathrm{R} \pm \mathrm{A} \underline{1569} \mathrm{P}:-97.8 \pm 1.6 \mathrm{mV}, \mathrm{n}=17 ; \mathrm{p}<0.001)$, while the slope factors were not

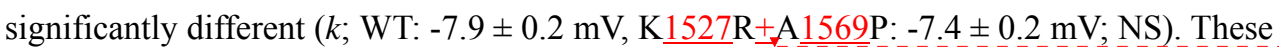
data show that activation is less-voltage dependent and the steady-state channel availability at voltages near the resting potentials is reduced in the mutant channel, Recovery from inactivation of the mutant channel fit with double exponential equation was nearly indistinguishable from WT (Fig 3C).

In addition to the fast inactivation, intermediate inactivation $\left(\mathrm{I}_{\mathrm{M}}\right)$, a distinct 
inactivation gating property with kinetics intermediate between fast and slow inactivation, has been implicated in Brugada syndrome ${ }^{18,19}$ (Fig 4A). Voltage-dependence of $\mathrm{I}_{\mathrm{M}}$ was evaluated by a $1 \mathrm{sec}$ prepulse of various potentials followed by a $20 \mathrm{~ms}$ brief recovery pulse to $-120 \mathrm{mV}$ to remove fast inactivation, and the channel availability was assessed by a $-20 \mathrm{mV}$ test pulse (Fig 4B). Voltage-dependence of steady-state $\mathrm{I}_{\mathrm{M}}$ fit with Boltzmann equation ${ }^{19}$ showed that the magnitude of $\mathrm{I}_{\mathrm{M}}$ is significantly larger in the mutant channel, $(\mathrm{WT}=0.20 \pm 0.02, \mathrm{n}=11$; $\mathrm{K} 1527 \mathrm{R}+\mathrm{A} 1569 \mathrm{P}=0.39 \pm 0.03, \mathrm{n}=13 ; \mathrm{p}<0.01)$ and the mid point of the curve was significantly shifted in the hyperpolarizing direction in the mutant channel, $\left(\mathrm{V}_{1 / 2} ; \mathrm{WT}=-92.9 \pm\right.$ $1.0 \mathrm{mV}, \mathrm{K} \underline{1527} \mathrm{R}+\mathrm{A} \underline{1569 \mathrm{P}}=-99.2 \pm 2.7 \mathrm{mV} ; \mathrm{p}<0.01)$. Slow inactivation was elicited by various lengths of prepulses at $-20 \mathrm{mV}$, and the time constant of $\mathrm{I}_{\mathrm{M}}$ obtained by fitting with a single exponential function was comparable $(\tau ; \mathrm{WT}=273 \pm 64 \mathrm{~ms}, \mathrm{~K} 1527 \mathrm{R} \pm \mathrm{A} \underline{1569 \mathrm{P}}=220 \pm$ $50 \mathrm{~ms}$ ); however, magnitude of the $\mathrm{I}_{\mathrm{M}}$ was significantly larger in the mutant channel, $(\mathrm{WT}=$ $0.18 \pm 0.02, \mathrm{n}=11 ; \mathrm{K} 1527 \mathrm{R} \pm \mathrm{A} \underline{1569} \mathrm{P}=0.39 \pm 0.03, \mathrm{n}=12 ; \mathrm{p}<0.05)$, showing enhanced entry to $I_{M}$ in the mutant channel. Recovery from $I_{M}$ was virtually identical between WT and the mutant channels, and co-expression of human $\mathrm{Na}$ channel $\beta_{1}$ subunit did not significantly change the gating properties of either WT or mutant channel channels (data not shown). These results suggest that the rate and the extent of $\mathrm{I}_{\mathrm{M}}$ are substantially enhanced in the mutant channel.

削除: KR/AP

削除: /

削除: KR/AP

削除: /

削除: /

削除: KR/AP

削除: /

削除: KR/AP

削除: KR/AP 


\section{Discussion}

Since the first identification of SCN5A mutations in the Brugada syndrome in $1998^{20}$, more than 50 distinct mutations have been reported. The functional properties of SCN5A mutations responsible for the Brugada syndrome show variable biophysical abnormalities including the following: (1) changes in Na channel gating properties ${ }^{18},(2)$ defective membrane trafficking ${ }^{21}$, or (3) a non-functional channel ${ }^{22}$. A common denominator of these mutations is a reduction of cardiac Na current leaving the transient outward $\mathrm{K}$ current $\left(\mathrm{I}_{\mathrm{to}}\right)$ unopposed in phase 1 , and a loss of the action potential dome in the right ventricular epicardium but not endocardium. The large transmural voltage-gradient in the right ventricle results in ST elevation in the right precordial leads and "phase 2 reentry" ${ }^{23}$. In contrast to the refined pathophysiology underlying the Brugada syndrome, it is still unclear whether the Brugada-type ECG is an electrocardiographic entity distinct from the Brugada syndrome, or whether it constitutes an asymptomatic subgroup of the Brugada syndrome sharing the same molecular and cellular abnormalities due to genetic defects in SCN5A.

In this study, we genetically screened 30 asymptomatic probands who showed a Brugada-type ECG without a family history of the disease, and identified a double SCN5A mutation, $\mathrm{K} 1527 \mathrm{R} \pm \mathrm{A} 1569 \mathrm{P} . ~ T h i s$ mutation is not only a novel SCN5A mutation associated 
with a Brugada-type ECG, but also the first naturally occurring double mutation in SCN5A, although a double mutation was previously reported in the Na channel gene (SCN4A) of skeletal muscle ${ }^{24}$. The prevalence of SCN5A mutation in asymptomatic individuals with a Brugada-type ECG in our study was only $3.3 \%$ and substantially lower than the $22 \%$ prevalence reported by Priori et al. in 130 probands with the Brugada syndrome ${ }^{12}$. There are several possible explanations for the apparent difference: 1) asymptomatic and symptomatic Brugada syndrome have distinct genetic bases, 2) ethnic variability between study populations, or 3) technical differences in genetic screening between laboratories. Recent genetic studies in the Brugada syndrome including both symptomatic and asymptomatic subjects in the Chinese population showed four SCN5A mutations in 5 (14\%) of 36 Brugada-syndrome probands (two symptomatic and three asymptomatic $)^{25}$, which is comparable to the recent study in Japanese population (4 out of $38 ; 11 \%$, Makiyama et al. personal communication). Therefore, the prevalence of SCN5A does not seem to be greatly affected by ethnicity. However, there was an important difference in the family history of sudden death between the study population of Priori et al. and our study. Priori et al. documented a family history of sudden death in 26 (20\%) of 130 probands ${ }^{12}$, while we had only one patient (case \#1) who had a family history of sudden death. The prevalence of a Brugada-type ECG in the general population is reported to be $0.1-0.7 \%$ in Japan, and the vast majority of the asymptomatic individuals exhibiting a Brugada-type ECG are sporadic ${ }^{6,7,26}$. These results suggest that asymptomatic individuals with 
a Brugada-type ECG most likely have a genetic background distinct from symptomatic Brugada syndrome patients.

Risk stratification of asymptomatic individuals with the Brugada syndrome is controversial. Brugada et al. showed that the prognosis of this patient group is unfavorable, and VF-inducibility is a good predictor of lethal arrhythmias ${ }^{8,27}$, whereas Priori et al. found no episodes of malignant arrhythmias over a period of 3 years in 30 asymptomatic patients with a Brugada sign ${ }^{9}$. We cannot precisely evaluate the prognostic value of PES or genetic testing in asymptomatic Brugada syndrome, because the case \#1 subject declined further examinations including PES or provocative drug testing, and no SCN5A mutations were identified. However, PES in our study showed relatively high VF inducibility (14 out of 17, $78 \%$ ) in asymptomatic individuals despite the fact that they remained asymptomatic, consistent with previous observations ( 8 out of $11 ; 73 \%)^{10}$. These results suggest that asymptomatic individuals with a Brugada-type ECG have a relatively benign prognosis, and that VF inducibility does not seem to be a good predictor of lethal events, at least for asymptomatic individuals without a family history of the Brugada syndrome. These results conflict with the observations of Brugada et al. who showed that individuals with inducible VF during PES have an elevated risk for lethal arrhythmias, and recommended prophylactic implantation of ICD for such individuals even though they are asymptomatic ${ }^{8,27}$. The reason 
for the discrepancy between studies is not clear, but it may be attributable in part to the enrollment of asymptomatic individuals with a family history of the Brugada syndrome.

Genetic screening of SCN5A is the most powerful diagnostic tool for the Brugada syndrome, especially for screening individuals within a family of a proband with an identified mutation. Demonstration of a novel mutation K1527R + A $1569 \mathrm{P}$ in our study suggests that genetic defects of SCN5A are at least partially responsible for a Brugada-type ECG in asymptomatic as well as symptomatic individuals. It is true that identification of a new mutation in a sporadic case is sometimes equivocal, and the existence of SCN5A mutations is not regarded as a reliable predicting value in the Brugada syndrome because of its substantially low sensitivity and specificity to identify patients with cardiac arrest ${ }^{12}$. However, it is plausible to speculate that functional evaluation of the SCN5A mutations may help to substantiate their pathophysiological relevance, which in turn may help stratify the risk of sudden death. Because the double mutant channel showed a negative shift of the steady-state inactivation curve and an increased proportion of $\mathrm{Na}$ channels that enter an intermediate state of inactivation, there is a reduction in cardiac Na current, which is characteristic of SCN5A mutations in those with symptomatic Brugada syndrome ${ }^{18,28}$. These results suggest that asymptomatic individuals with "functionally proven" SCN5A mutations with loss-of-function properties should be carefully followed to avoid lethal events as was observed in the SUNDS 
victim case \#1. Further clinical and genetic studies with larger population and longer

follow-up period are required to evaluate the predicting value of SCN5A mutations with loss-of-function properties in asymptomatic subjects.

Despite exhibiting typical coved-type ST elevation and severe functional defect in cardiac $\mathrm{Na}$ channel, the case \#2 subject remains asymptomatic, but the underlying genetic, cellular, or electrophysiological mechanisms are not clear. Clinical consequences of SCN5A mutations are usually determined by the functional properties of each mutation, leading to multiple distinct cardiac Na channelopathies including Brugada syndrome, LQT3, and cardiac conduction defect. However, there are several lines of evidence that do not agree with the abovementioned idea. Silent SCN5A mutation carriers are occasionally observed in the pedigrees of in Brugada syndrome families ${ }^{29}$ as well as in long-QT syndrome ${ }^{30}$. We previously found an $S C N 5 A$ mutation $\mathrm{R} 367 \mathrm{H}$ in a family with atrial standstill complicated with $\mathrm{J}$ wave elevation in the inferior leads ${ }^{22}$, while Hong et al. found the same mutation in a typical Brugada syndrome family ${ }^{31}$. Moreover, a single mutation G1406R results in Brugada syndrome or cardiac conduction defect in the same family ${ }^{32}$. These results suggest that the clinical consequence of the some SCN5A mutations are occasionally determined in individual-specific or branch-specific manners, rather than mutation-specific manner. Based on these observations, it is speculated that the severe functional defects of the double 
mutation observed in asymptomatic subject $\# 2$ are not necessarily sufficient to manifest syncope or life-threatening arrhythmias, and the clinical consequence of the mutations may be greatly influenced by some unknown environmental factors or genetic modifiers.

Our clinical and genetic study enrolled only 30 individuals with a Brugada-type ECG, and further studies in a larger population with a longer evaluation period are required to draw definitive conclusions with respect to the pathogenesis and risk stratification of this disease entity. In parallel with efforts to establish new parameters with high predictive value ${ }^{33,34}$, further genetic screening of $S C N 5 A$ and identification of new responsible genes are required for demonstrating the molecular basis for both symptomatic and asymptomatic Brugada syndrome.

\section{Conclusions}

$\underline{\text { Asymptomatic individuals with a Brugada-type ECG generally have a better prognosis }}$ than their symptomatic counterparts, but there may be a subgroup of these individuals with poor prognosis. Na channel dysfunction due to SCN5A mutation may be responsible, at least in part, for a Brugada-type ECG in asymptomatic individuals. Severe functional defect of SCN5A mutations may not be sufficient to cause symptoms, and some environmental factors or modifier genes may play additional roles for the arrhythmogenesis. Although the efficacy 
of genetic screening is not sufficiently high to use as a diagnostic tool in the presence of a Brugada-type ECG in asymptomatic individuals, further clinical and genetic studies are required for elucidating the pathophysiology of Brugada syndrome, which in turn provide more efficient treatment of family members who are still asymptomatic.

\section{Acknowledgements}

The authors thank Dr. Alfred L. George Jr. for critical reading of the manuscript and providing comments. We also thank A. Aita and K. Morisaki for technical assistance. 


\section{References}

1. Brugada P, Brugada J. Right bundle branch block, persistent ST segment elevation and sudden cardiac death: a distinct clinical and electrocardiographic syndrome. A multicenter report. J Am Coll Cardiol 1992;20:1391-1396.

2. Wilde AA, Antzelevitch C, Borggrefe M, Brugada J, Brugada R, Brugada P, Corrado D, Hauer RN, Kass RS, Nademanee K, Priori SG, Towbin JA. Proposed diagnostic criteria for the Brugada syndrome. Eur Heart J 2002;23:1648-1654.

3. Antzelevitch C. The Brugada syndrome: ionic basis and arrhythmia mechanisms. J Cardiovasc Electrophysiol 2001;12:268-272.

4. Vatta M, Dumaine R, Varghese G, Richard TA, Shimizu W, Aihara N, Nademanee K, Brugada R, Brugada J, Veerakul G, Li H, Bowles NE, Brugada P, Antzelevitch C, Towbin JA. Genetic and biophysical basis of sudden unexplained nocturnal death syndrome (SUNDS), a disease allelic to Brugada syndrome. Hum Mol Genet $2002 ; 11: 337-345$.

5. Hermida JS, Lemoine JL, Aoun FB, Jarry G, Rey JL, Quiret JC. Prevalence of the brugada syndrome in an apparently healthy population. Am J Cardiol 2000;86:91-94.

6. Matsuo K, Akahoshi M, Nakashima E, Suyama A, Seto S, Hayano M, Yano K. The prevalence, incidence and prognostic value of the Brugada-type electrocardiogram: A 
population-based study of four decades. J Am Coll Cardiol 2001;38:765-770.

7. Miyasaka Y, Tsuji H, Yamada K, Tokunaga S, Saito D, Imuro Y, Matsumoto N, Iwasaka T. Prevalence and mortality of the Brugada-type electrocardiogram in one city in Japan. J Am Coll Cardiol 2001;38:771-774.

8. Brugada J, Brugada R, Antzelevitch C, Towbin J, Nademanee K, Brugada P. Long-term follow-up of individuals with the electrocardiographic pattern of right bundle-branch block and ST-segment elevation in precordial leads V1 to V3. Circulation 2002;105:73-78.

9. Priori SG, Napolitano C, Gasparini M, Pappone C, Della Bella P, Brignole M, Giordano U, Giovannini T, Menozzi C, Bloise R, Crotti L, Terreni L, Schwartz PJ. Clinical and genetic heterogeneity of right bundle branch block and ST- segment elevation syndrome : A prospective evaluation of 52 families. Circulation 2000;102:2509-2515.

10. Takenaka S, Kusano KF, Hisamatsu K, Nagase S, Nakamura K, Morita H, Matsubara H, Emori T, Ohe T. Relatively benign clinical course in asymptomatic patients with brugada- type electrocardiogram without family history of sudden death. J Cardiovasc Electrophysiol 2001;12:2-6.

11. Atarashi H, Ogawa S, Harumi K, Sugimoto T, Inoue H, Murayama M, Toyama J, Hayakawa H. Three-year follow-up of patients with right bundle branch block and ST 
segment elevation in the right precordial leads: Japanese Registry of Brugada Syndrome. Idiopathic Ventricular Fibrillation Investigators. J Am Coll Cardiol 2001;37:1916-1920.

12. Priori SG, Napolitano C, Gasparini M, Pappone C, Della Bella P, Giordano U, Bloise R, Giustetto C, De Nardis R, Grillo M, Ronchetti E, Faggiano G, Nastoli J. Natural history of Brugada syndrome: insights for risk stratification and management.

Circulation 2002;105:1342-1347.

13. Takenaka S, Emori T, Koyama S, Morita H, Fukushima K, Ohe T. Asymptomatic form of Brugada syndrome. Pacing Clin Electrophysiol 1999;22:1261-1263.

14. Wang Q, Li Z, Shen J, Keating MT. Genomic organization of the human SCN5A gene encoding the cardiac sodium channel. Genomics 1996;34:9-16.

15. Sambrook J, Russell D, W., eds. Molecular cloning: a laboratory manual. Third edition ed. Cold Spring Harbor, NY: Cold Spring Harbor Laboratory Press; 2001.

16. Makita N, Horie M, Nakamura T, Ai T, Sasaki K, Yokoi H, Sakurai M, Sakuma I, Otani H, Sawa H, Kitabatake A. Drug-induced long-QT syndrome associated with a subclinical SCN5A mutation. Circulation 2002;106:1269-1274.

17. Bennett PB, Yazawa K, Makita N, George AL, Jr. Molecular mechanism for an inherited cardiac arrhythmia. Nature 1995;376:683-685.

18. Wang DW, Makita N, Kitabatake A, Balser JR, George AL, Jr. Enhanced $\mathrm{Na}^{+}$channel 
intermediate inactivation in Brugada syndrome. Circ Res 2000;87:E37-43.

19. Veldkamp MW, Viswanathan PC, Bezzina C, Baartscheer A, Wilde AA, Balser JR.

Two distinct congenital arrhythmias evoked by a multidysfunctional $\mathrm{Na}^{+}$channel. Circ Res 2000;86:E91-97.

20. Chen Q, Kirsch GE, Zhang D, Brugada R, Brugada J, Brugada P, Potenza D, Moya A, Borggrefe M, Breithardt G, Ortiz-Lopez R, Wang Z, Antzelevitch C, O'Brien RE, Schulze-Bahr E, Keating MT, Towbin JA, Wang Q. Genetic basis and molecular mechanism for idiopathic ventricular fibrillation. Nature 1998;392:293-296.

21. Valdivia CR, Tester DJ, Rok BA, Porter C-bJ, Munger TM, Jahangir A, Makielski JC, Ackerman MJ. A trafficking defective, Brugada syndrome-causing SCN5A mutation rescued by drugs. Cardiovasc Res 2004;62:53-62.

22. Takehara N, Makita N, Kawabe J, Sato N, Kawamura Y, Kitabatake A, Kikuchi K. A cardiac sodium channel mutation identified in Brugada syndrome associated with atrial standstill. J Intern Med 2004;255:137-142.

23. Antzelevitch C. The Brugada syndrome: diagnostic criteria and cellular mechanisms. Eur Heart J 2001;22:356-363.

24. Bendahhou S, Cummins TR, Hahn AF, Langlois S, Waxman SG, Ptacek LJ. A double mutation in families with periodic paralysis defines new aspects of sodium channel slow inactivation. J. Clin. Invest. 2000;106:431-438. 
25. Mok NS, Priori SG, Napolitano C, Chan KK, Bloise R, Chan HW, Fung WH, Chan YS, Chan WK, Lam C, Chan NY, Tsang HH. Clinical profile and genetic basis of Brugada syndrome in the Chinese population. Hong Kong Med J 2004;10:32-37.

26. Furuhashi M, Uno K, Tsuchihashi K, Nagahara D, Hyakukoku M, Ohtomo T, Satoh S, Nishimiya T, Shimamoto K. Prevalence of asymptomatic ST segment elevation in right precordial leads with right bundle branch block (Brugada-type ST shift) among the general Japanese population. Heart 2001;86:161-166.

27. Brugada J, Brugada R, Brugada P. Determinants of sudden cardiac death in individuals with the electrocardiographic pattern of Brugada syndrome and no previous cardiac arrest. Circulation 2003;108:3092-3096.

28. Balser JR. The cardiac sodium channel: gating function and molecular pharmacology. J Mol Cell Cardiol 2001;33:599-613.

29. Priori SG, Napolitano C, Memmi M, Colombi B, Drago F, Gasparini M, DeSimone L, Coltorti F, Bloise R, Keegan R, Cruz Filho FE, Vignati G, Benatar A, DeLogu A. Clinical and molecular characterization of patients with catecholaminergic polymorphic ventricular tachycardia. Circulation 2002;106:69-74.

30. Priori SG, Napolitano C, Schwartz PJ. Low penetrance in the long-QT syndrome: clinical impact. Circulation 1999;99:529-533.

31. Hong K, Berruezo-Sanchez A, Poungvarin N, Oliva A, Vatta M, Brugada J, Brugada P, 
Towbin JA, Dumaine R, Pinero-Galvez C, Antzelevitch C, Brugada R. Phenotypic characterization of a large European family with Brugada syndrome displaying a sudden unexpected death syndrome mutation in SCN5A. J Cardiovasc Electrophysiol 2004;15:64-69.

32. Kyndt F, Probst V, Potet F, Demolombe S, Chevallier JC, Baro I, Moisan JP, Boisseau P, Schott JJ, Escande D, Le Marec H. Novel SCN5A mutation leading either to isolated cardiac conduction defect or Brugada syndrome in a large French family. Circulation 2001;104:3081-3086.

33. Ikeda T, Sakurada H, Sakabe K, Sakata T, Takami M, Tezuka N, Nakae T, Noro M, Enjoji Y, Tejima T, Sugi K, Yamaguchi T. Assessment of noninvasive markers in identifying patients at risk in the Brugada syndrome: insight into risk stratification. $\mathrm{J}$ Am Coll Cardiol 2001;37:1628-1634.

34. Atarashi H, Ogawa S. New ECG criteria for high-risk Brugada syndrome. Circ J 2003;67:8-10. 
Figure Legends

\section{Fig. 1 Electrocardiographic findings}

(A) (B) Twelve-lead ECG recording of the two cases of asymptomatic Brugada syndrome.

(A) and (B) show the ECGs of case 1 (sudden death) and case 2 (double SCN5A

mutation), respectively. Coved-type elevation (A) and saddle-back ST elevation (B)

in the right precordial leads are noted (arrows).

Fig 2. Molecular genetics of the case 2

(A) Exon 27 of the SCN5A was amplified from the genomic DNA and was subjected to PCR-SSCP analysis. Lanes 1-3: healthy control individuals. Lane 4: case 2. An aberrant conformer is shown with arrows.

(B) Direct DNA sequencing of the exon 27. Heterozygous nucleotide changes A4580G and $\mathrm{G} 4705 \mathrm{C}$ resulting in missense mutations K1527R and A1569P, respectively.

(C) Predicted topology of the cardiac Na channel Nav1.5 and the location of the two mutations K1527R and A1569P. Transmembrane segments (S1-S6) in each domain (D1-D4) are shown with boxes.

Fig 3. Biophysical properties of the double mutation.

削除: nt channel

削除: KR/AP 
(A) Representative whole-cell current traces obtained from tsA-201 transfected with WT or $\mathrm{K} 1527 \mathrm{R}+\mathrm{A} 1569 \mathrm{P}, \mathrm{Na}$ channels. Currents were recorded from a holding potential of $-120 \mathrm{mV}$ and stepped from $-90 \mathrm{mV}$ to $+90 \mathrm{mV}$ during $20 \mathrm{~ms}$ in $10 \mathrm{mV}$ increments. Currents were normalized and superimposed.

(B) Voltage-dependence of activation and the steady-state fast inactivation of WT (open circles) and $\mathrm{K} 1527 \mathrm{R}+\mathrm{A} 1569 \mathrm{P}$ (filled squares). Current-voltage relationship was fit to the Boltzmann equation: $\mathrm{I} / \mathrm{I}_{\max }=\left(\mathrm{V}-\mathrm{V}_{\text {rev }}\right) \times\left(1+\exp \left(\mathrm{V}-\mathrm{V}_{1 / 2}\right) / \mathrm{k}\right)^{-1}$, where $\mathrm{I}_{\max }$ represents the maximum peak current, and $\mathrm{V}, \mathrm{V}_{\text {rev }}, \mathrm{V}_{1 / 2}$ is the test pulse potential, reversal potential, and the mid point of activation, respectively. Conductance $(\mathrm{G})$ was calculated by the equation $\mathrm{G}=\mathrm{I} \times\left(\mathrm{V}-\mathrm{V}_{\text {rev }}\right)^{-1}$, and the normalized peak conductance was plotted as a function of membrane potential. To assess steady-state fast inactivation, the peak currents were measured during a $-20 \mathrm{mV}$ test potential after a series of $100 \mathrm{~ms}$ prepulses from $-150 \mathrm{mV}$ to $-30 \mathrm{mV}$. Normalized peak current was plotted as a function of prepulse potential. Steady-state fast inactivation curve was fit with the Boltzmann equation: $\mathrm{I} / \mathrm{I}_{\max }=\left(1+\exp \left(\left(\mathrm{V}-\mathrm{V}_{1 / 2}\right) / k\right)\right)^{-1}$. Activation of the mutant channel was significantly less voltage-dependent and the steady-state inactivation curve was significantly shifted in a negative direction $\left(\mathrm{V}_{1 / 2}\right.$ : WT $=-88.6 \pm 1.0 \mathrm{mV}, \mathrm{n}=$

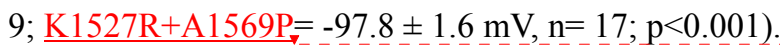

削除: KR/AP 
(C) Recovery from inactivation was assessed by a standard double pulse protocol consisted of a $500 \mathrm{~ms}$ conditioning pulse, followed by a various length $(\Delta \mathrm{t})$ of recovery interval at $-120 \mathrm{mV}$, and a test pulse $(-20 \mathrm{mV}, 50 \mathrm{~ms})$. Normalized peak current was fit to a double exponential function: $\mathrm{I} / \mathrm{I}_{\max }=\mathrm{C}-\mathrm{A}_{\mathrm{f}} \times \exp \left(-\mathrm{t} / \tau_{\mathrm{f}}\right)-\mathrm{A}_{\mathrm{s}} \times$ $\exp \left(-\mathrm{t} / \tau_{\mathrm{s}}\right)$

\section{Fig 4. Intermediate inactivation properties of the double mutant channel}

(A) Voltage-dependence of $\mathrm{I}_{\mathrm{M}}$ was determined by a double pulse protocol shown in the inset. Cells were depolarized for $1 \mathrm{~s}$ by a prepulse with various potentials ranging from $-150 \mathrm{mV}$ to $-30 \mathrm{mV}$ to elicit $\mathrm{I}_{\mathrm{M}}$, followed by a $20 \mathrm{~ms}$ repolarization at $-120 \mathrm{mV}$ to allow recovery from fast inactivation. The remaining $\mathrm{Na}$ currents were measured with a test pulse $-20 \mathrm{mV}$ and the normalized currents were fit with the Boltzmann equation, $\left.\mathrm{I} / \mathrm{I}_{\max }=\mathrm{A} \times\left(1+\exp \left(\left(\mathrm{V}-\mathrm{V}_{1 / 2}\right) / k\right)\right)\right)^{-1}+\mathrm{C}$ to determine the fraction $\mathrm{I}_{\mathrm{M}}(\mathrm{A})$ and the membrane potential for half maximal inactivation $\left(\mathrm{V}_{1 / 2}\right)^{19}$.

(B) Time course of the development of $\mathrm{I}_{\mathrm{M}}$. Cells were depolarized at $-20 \mathrm{mV}$ for a various length of time $(\Delta t)$ to elicit $\mathrm{I}_{\mathrm{M}}$, followed by a brief repolarization to allow recovery from fast inactivation. The remaining Na currents were measured at a test pulse to $-20 \mathrm{mV}$. Normalized peak current were fit with a monoexponential equation: $\mathrm{I} / \mathrm{I}_{\max }=\mathrm{A} \times \exp (-\mathrm{t} / \tau)+\mathrm{C}$, where $\mathrm{A}$ is the fraction of $\mathrm{I}_{\mathrm{M}}$, and $\tau$ is the time constant. 
Magnitude of $I_{M}$ was significantly enhanced in the mutant channel (WT $=0.18 \pm 0.02$, $\mathrm{n}=11 ; \mathrm{K} 1527 \mathrm{R}+\mathrm{A} 1569 \mathrm{P}=0.25 \pm 0.03, \mathrm{n}=12 ; \mathrm{p}<0.05)$, while the time constant for the 削除: / development of $\mathrm{I}_{\mathrm{M}}$ was comparable. 
